Alberto Puppo

«LOS ROSTROS DE LA CIENCIA JURÍDICA ENTRE ACEPTACIÓN, DESCRIPCIÓN E INSCRIPCIÓN DEL DERECHO» 


\title{
LOS ROSTROS DE LA CIENCIA JURÍDICA ENTRE ACEPTACIÓN, DESCRIPCIÓN E INSCRIPCIÓN DEL DERECHO
}

\author{
Alberto Puppo \\ Universidad de ParísX - Nanterre
}

\section{Introducción}

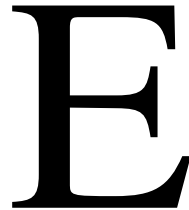

1 problema que quiero afrontar no es nuevo ${ }^{1}$; se podría situar seguramente entre los problemas clásicos de la teoría del derecho. La novedad, si la hay, reside en el hecho de que algunos de los conceptos fundamentales que lo delimitan han recibido en los últimos años contribuciones dignas de consideración ${ }^{2}$.

En efecto, trataré del papel de los estudiosos del derecho en la identificación de un ordenamiento jurídico y en la determinación de su contenido; el tratamiento de este tema presupone, por tanto, el problema de la existencia de los ordenamientos jurídicos e, indirectamente, del conocimiento jurídico ${ }^{3}$.

Mi exposición se compone de cuatro partes.

En la primera parte trato de reconstruir el concepto de punto de vista interno y el concepto de aceptación; de aquí surgirá que el punto de vista interno se compone de dos elementos, uno cognitivo y otro volitivo, cada uno de los cuales mantiene una relación típica con la aceptación. Se distinguirá a continuación entre aceptación en sentido cognitivo, o reconocimiento, y aceptación en sentido volitivo, o aceptación en sentido fuerte; emergerá además un tercer tipo de aceptación, totalmente formal, consistente en la asunción de algunas normas como premisas en sentido lógico de un razo-

${ }^{1}$ Cfr., por ejemplo, M. Jori (1985), p. 122, quien, explícitamente, después de haberse referido a los tres tipos de discurso (interno, externo y externo moderado) elaborados por Hart, se plantea el problema de dónde deben situarse «los discursos con los cuales los juristas iuspositivistas (entre los cuales se encuentra también Hart) describen el derecho»; Jori, entre otros, manifiesta un cierto estupor ante el silencio hartiano sobre esta cuestión fundamental.

${ }^{2}$ Un solo ejemplo: C. Redondo (1996).

${ }^{3}$ Cfr. M. Jori (1985), p. 211, quien subraya que preguntarse acerca de la naturaleza de la descripción del derecho implica adentrarse en una «constelación de problemas, que van del problema de la naturaleza y existencia de la norma jurídica al de la validez, la interpretación, la eficacia, la definición (del concepto) de derecho, la norma fundamental y otros más. 
namiento. La conclusión de esta primera parte es simplemente que no conviene introducir el concepto de aceptación para explicar el concepto de derecho sin especificar en qué sentido y en qué contexto se quiere utilizar tal concepto.

En la segunda parte, recorriendo las líneas fundamentales de la literatura analítico-positivista, reconstruyo las peculiaridades del punto de vista del jurista y del discurso que éste pronuncia. Es generalmente compartida, salvo por algunas diferencias terminológicas, la tesis de que el jurista reconoce, esto es, acepta cognitivamente, el objeto de sus descripciones, pero no se compromete en un plano moral o político con las normas descritas. En efecto, se admite la posibilidad de que el jurista describa el derecho por medio de enunciados externos o internos distanciados, sin aceptar en sentido pleno, esto es, desde un punto de vista externo moderado, o hermenéutico; una importante voz disonante, en la que se inscribe mi análisis, es la de Scarpelli, quien, por el contrario, no exime el discurso del jurista de la responsabilidad moral inherente a la aceptación en sentido fuerte del ordenamiento jurídico al cual pertenecen las normas descritas.

La tercera parte está dedicada a la distinción entre los diversos sujetos y objetos del discurso jurídico. Así, la adopción de un punto de vista interno se puede presentar bajo diversas formas. Desde la doctrina en sentido estricto hasta la filosofía del derecho, y desde la teoría de la norma hasta la teoría del derecho, el proceso conocimiento-aceptación-descripción es activado continuamente, y no se debe por tanto decretar de una vez por todas si un jurista, no mejor cualificado, adopta un punto de vista interno y acepta (en uno de los sentidos precisados) una de las entidades que constituyen el objeto de su discurso ${ }^{4}$.

En la última parte sostengo una tesis sobre el papel del jurista en la identificación del derecho. Utilizando la imagen del universo jurídico (no sólo,

\footnotetext{
4 Todavía quedarían en mi opinión dos cuestiones que afrontar: es necesario preguntarse si se puede aceptar sin conocer y si el acto de conocer no implica en realidad un elemento intencional que podría volver superfluo el componente volitivo del cual se ha hablado. A la primera cuestión (que no es muy interesante desde el punto de vista de la ciencia jurídica, de cuyo conocimiento no sería sensato dudar), R. Shiner (1992), pp. 174 ss., parece responder positivamente cuando dice que el hecho de que algunos sujetos se comporten conforme a la norma de modo irreflexivo, como borregos, es compatible con el punto de vista interno. Me parece, por otro lado, que también para Shiner el conocimiento es presupuesto; aquello que se pone en crisis no es la relación de dependencia entre aceptación y conocimiento, sino el concepto de conocimiento. Todo esto depende en gran medida del enfoque aristotélico del análisis de Shiner y no suscita por el momento un interés particular; podría decirse, por utilizar el vocabulario elegido para mi análisis, que siguiendo a Shiner me colocaría fuera de la perspectiva en la que intento profundizar. Para dar cuenta de las otras elaboraciones del concepto de aceptación necesariamente debo aceptar algunos presupuestos teóricos, enumerados al principio de este trabajo, que legitiman dicho análisis.
} 
por tanto, del ordenamiento jurídico) como estructurado jerárquicamente y la teoría de los niveles del discurso, sostendré que todo acto aparentemente descriptivo implica, de un lado, aceptación de las reglas superiores que hacen posible, es decir, inteligible, el discurso «descriptivo»; de otro, la creación, la inscripción, en el universo jurídico de las reglas que a un nivel inferior fueron aceptadas e hicieron posible la creación de otras reglas. El hecho de que en un cierto nivel se interrumpa el recorrido que conduce al descubrimiento de los fundamentos no constituye una necesidad lógica, sino más bien una exigencia pragmática. El derecho es lenguaje pero, en primer lugar, es un instrumento para influir en los comportamientos. Si bien el lenguaje puede ser usado para influir en los comportamientos, sólo un salto hacia la acción (salir del lenguaje) interrumpe la espiral que conduce el derecho a la moral y la teoría del derecho a la filosofía moral. Un corolario de esta tesis es que si se rechaza la idea de que todo el derecho ha sido creado por los juristas (sin olvidar que el juez, en la medida en que interpreta, es jurista), entonces es necesario revisar seriamente las teorías que reducen el derecho a la expresión de la voluntad del soberano o, en general, a las órdenes (como las del bandido), así como aquellas, como las realistas, que reducen el derecho al resultado de la actividad decisoria de los funcionarios.

En breve, la cuestión que me propongo, y que recorre las cuatro partes de mi trabajo, es la siguiente: ¿qué puntos de vista puede adoptar el jurista positivista cuando describe el derecho?

Quizá convenga aclarar el sentido de esta pregunta.

La pregunta podría formularse de manera distinta. Derivando hacia un estudio sociológico, podría haberme preguntado qué puntos de vista adoptan de hecho los juristas. Sin embargo, esta investigación estaría abocada al fracaso, porque la noción de punto de vista resulta muy imprecisa. Considero imprecisa la noción de punto de vista tan sólo a los fines de un análisis empírico. En la actividad que consiste en adoptar un punto de vista entran en juego muchos elementos de naturaleza psicológica; si no se acepta la reducción de la adopción de un punto de vista interno a la enunciación de enunciados internos, y si se problematiza la cualidad que hace que un enunciado sea «interno», la efectiva adopción de un punto de vista queda como algo de difícil, si no imposible, relevancia empírica.

También habría podido, situándome en un punto de vista normativo, preguntarme qué puntos de vista deberían adoptar los juristas; este enfoque, sin embargo, es ajeno a mis intenciones.

Mi pregunta puede ser reducida a una investigación acerca de la coherencia entre algunas tesis teóricas generalmente aceptadas en el ámbito positivista: si se acepta un planteamiento analítico y una concepción del derecho en algún sentido positivista, si se acepta la distinción entre lenguaje 
descriptivo y lenguaje prescriptivo, si se acepta la distinción entre punto de vista interno y punto de vista externo en alguna de las posibles versiones que se han propuesto a partir de Hart y, en definitiva, si se toma como referencia la actividad del jurista en un estado constitucional, ¿qué punto de vista se puede atribuir al jurista que describe el derecho sin renunciar a alguno de estos postulados? En otros términos, me pregunto si existe una tesis sobre la descripción del derecho que hace el jurista que sea compatible con las tesis teóricas antes enunciadas.

Por tanto, se podría catalogar mi análisis, a condición de aceptar determinadas categorías, con los términos de metateoría o metametodología del derecho.

Las cuestiones conexas son las siguientes: ¿existe un sólo tipo de juristas o es necesario distinguir entre varias clases de estudiosos del derecho? ¿Qué relación existe entre la adopción de un punto de vista interno respecto a la norma jurídica, el sistema jurídico o el ordenamiento jurídico y la aceptación de tales entidades? Esto equivale a preguntarse qué significa adoptar un punto de vista interno y, sobre todo, qué significa adoptar un punto de vista interno respecto del derecho; $y$, además, de acuerdo con la definición corriente de punto de vista interno, cuál es la naturaleza del acto de aceptación. En definitiva: ¿en qué sentido se acepta la regla de reconocimiento?

Resulta evidente que estas importantes cuestiones no pueden ser abordadas exhaustivamente; trataré cada una de ellas en la medida en que sea necesario para la elaboración de mi tesis.

En particular, sostendré que -desde el punto de vista de una teoría del derecho positivista que se quiera liberar de formas ingenuas de imperativismo y que considere al derecho como lenguaje- la ciencia jurídica, en el cumplimiento de la actividad que comúnmente es definida como descripción del derecho, crea en sentido fuerte el derecho, esto es, crea las reglas de identificación y las reglas de interpretación a través de las cuales se llega al conocimiento del contenido del derecho.

El trabajo de la ciencia jurídica consiste fundamentalmente en proporcionar la gramática y el vocabulario del derecho. En este sentido, sostengo que la ciencia jurídica, más que describir (el sociólogo del derecho describe) o prescribir (el legislador prescribe), se dedica a escribir el derecho 5 .

${ }^{5}$ Como sostiene M. Barberis (1990), p. 301: «los conceptos y las instituciones fundamentales, antes de ser recibidos por el legislador y/o por el juez, son a menudo construcciones doctrinales» y «para saber cuál es el derecho vigente es necesario frecuentemente recurrir al auxilio de la doctrina»; cfr. también G. Tarello (1980), p. 32, según el cual «la sistemática de los intérpretes es una ulterior fuente extralegislativa del derecho». 
Como ya he precisado, mi propósito no es normativo; me parece por tanto perfectamente aceptable que se sostenga una teoría de tipo hobbesiano o austiniano o realista radical; lo que sostengo es que, si por cualquier motivo se rechaza una solución radical, o banal, o no suficientemente atenta a la realidad social de los ordenamientos jurídicos complejos propios del mundo contemporáneo, o moralmente comprometida, etc., esto es, si nos movemos sobre la estela de Hart y del filón de la hermenéutica analítica en una perspectiva que problematiza la relación entre voluntad del legislador, normatividad de trozos de papel y discrecionalidad, al menos parcial, de la actividad interpretativa, entonces mi tesis es correcta.

\section{Punto de vista interno y aceptación (describiendo, con distanciamiento, el punto de vista de Hart)}

El punto de vista interno ha sido definido por Hart como aquel que adoptan quienes aceptan y usan las normas como guía de comportamiento: «it is possible to be concerned with the rules [...] as a member of the group which accepts and uses them as guides of conduct» ${ }^{6}$.

Para MacCormik el punto de vista interno se compone de dos elementos, uno cognitivo y otro volitivo. El elemento cognitivo consiste en la capacidad de concebir un modelo de conducta; el elemento volitivo consiste en la preferencia, en el empeño de la voluntad a favor del comportamiento que constituye una realización de un cierto modelo de conducta ${ }^{7}$.

${ }^{6}$ Cfr. H.L.A. Hart (1961), p. 86. No se puede ignorar, y debe tenerse siempre presente, que todo, o al menos la mayor parte, de lo que Hart y la mayoría de sus comentaristas anglosajones han escrito para definir el punto de vista interno está referido a los destinatarios de las normas o a los funcionarios (que también son destinatarios). Para una bibliografía, no limitada al mundo anglosajón, de los primeros comentarios a la obra de Hart, cfr. A. Catania (1987), p. 18, nota 1; para algunas de las obras monográficas más recientes, cfr. M. Martin (1987), R. Moles (1987).

${ }^{7}$ Cfr. H.L.A. Hart (1961), pp. 87-88; N. MacCormik (1978), 275-292, y N. MacCormik (1982), par. 2, donde se subraya que tales preferencias normalmente estarán fundadas sobre valores; cfr. también J.C. Bayón (1991), para quien en la definición hartiana de punto de vista interno «se presentan como si fuesen inescindibles la comprensión de fenómenos sociales en términos de seguimiento de reglas [...] y la aceptación de esas mismas reglas». Siempre desde una perspectiva hermenéutica, y en línea con el análisis de MacCormik, el concepto de punto de vista interno, y en particular la expresión «actitud crítica reflexiva» que, siguiendo a Hart, lo define, está compuesto, según V. Villa (1993), p. 268, de dos elementos: «el primero [...] de carácter cognitivo ("reflexivo"), que implica para los miembros del grupo la capacidad de rendir cuentas del modelo de comportamiento previsto en la norma (en alguna de sus interpretaciones "standard"), y, por tanto, de saber cuándo su conducta se adecua o no al modelo mismo [...] el segundo es un elemento que pertenece a la esfera de la voluntad ("crítico") y concierne al deseo o la preferencia [...] de que su comportamiento sea acorde con el modelo previsto». Por lo que respecta al componente constituido por la preferencia es interesante recordar que para MacCormick (1981), p. 36, el acto de no aceptación, el rechazo de una norma, no implica la ausencia de una preferencia positiva a favor de la conformidad al modelo de conducta, 
Por otra parte, estos dos componentes pueden estar separados. Para comprender el fenómeno jurídico es necesario adoptar una posición cognitivamente interna ${ }^{8}$, que no implica todavía la voluntad de someterse a la norma a la cual se hace referencia. En un sentido similar, Navarro y Redondo han sostenido que la aceptación de una norma presupone que el sujeto conozca el contenido normativo y que tenga una actitud positiva hacia ella. La aceptación proporciona una razón para el sujeto que elige conformarse al precepto; incluso una vez que se ha subrayado que la expresión «aceptación de una norma» es ambigua y «oculta diferencias relevantes entre las actitudes de los sujetos y los objetos a los que se dirige» ${ }^{9}$. Digna de interés es la definición del elemento volitivo en términos de una simple «actitud positiva». Esta noción queda aclarada en la serie de análisis de los autores ${ }^{10}$ : La aceptación puede manifestarse, por ejemplo, en admitir como justificada la crítica correspondiente a la desviación respecto del modelo prescrito en la norma, o bien, simplemente, en el uso del lenguaje normativo para valorar un modelo de comportamiento; por lo que se refiere al objeto de la aceptación, resulta interesante la hipótesis de que los sujetos se limitan a reconocer que en ciertos contextos deben guiar su propia conducta de acuerdo con normas jurídicas; cuando esto es así, al prescindir del contenido de la norma se acepta el hecho de que en determinadas circunstancias la reglamentación jurídica es necesaria, se acepta «la existencia institucional de las normas» ${ }^{11}$.

sino más bien «an active preference for non-conformity». Por ello, el rechazo también presupondría la adopción del punto de vista interno. En el mismo sentido, P. M. Hacker (1966), p. 177: «El rechazo de las reglas presupone el conocimiento de su existencia». Y además también aquellos que rechazan utilizan el discurso interno, «tienen necesidad de lenguaje normativo del "deber" para justificar sus predicciones desde el punto de vista externo [...]».

${ }^{8}$ R. Guastini (1977a), pp. 432-433, distingue entre el punto de vista interno respecto de una definición (en nuestro caso, del modelo de conducta), cognitivamente interno, y el punto de vista interno respecto de una norma (en nuestro caso, que califica deónticamente un modelo de conducta), normativamente interno.

${ }^{9}$ Cfr. P. Navarro - C. Redondo (1991), p. 230. Suscita inmediatamente un vivo interés una circunstancia que ilustra bien la dificultad del problema: MacCormik, Villa, Navarro y Redondo predican más o menos la misma cualidad de tres objetos diversos, al menos nominalmente: Navarro y Redondo hablan de aceptación, MacCormik de punto de vista interno, Villa de actitud crítica reflexiva. Parecería por ello, aunque en realidad no es así, que hay coincidencia entre los sujetos que adoptan un punto de vista interno, que asumen una actitud crítica y que aceptan.

${ }^{10}$ Cfr. P.Navarro - C. Redondo (1991).

${ }^{11}$ Cfr. P. Navarro - C. Redondo (1991), pp. 230-231. En el mismo sentido, R. Guastini (1997a), pp. 417 ss., que, criticando las tesis de Scarpelli (sobre las cuales, véase infra) distingue entre aceptación en sentido fuerte y aceptación en sentido débil o «reconocimiento»: «el mero reconocimiento tiene como objeto las (otras) normas del ordenamiento, previa aceptación del principio fundamental». 
Es necesario preguntarse ahora qué relación existe entre los dos componentes del punto de vista interno. Parece generalmente aceptada la tesis según la cual el componente cognitivo y el volitivo no están en el mismo nivel: el segundo presupone al primero, el conocimiento es presupuesto de la aceptación ${ }^{12}$.

Esto sugiere la siguiente hipótesis: el punto de vista interno debe ser definido únicamente en términos epistemológicos, en términos de conocimiento; como ha sostenido Sartorius ${ }^{13}$ en contra de MacCormik, el elemento volitivo no es constitutivo del punto de vista interno, sino, eventualmente, añado yo, de la aceptación ${ }^{14}$.

Por tanto, se trataría de separar decididamente el concepto de aceptación del de punto de vista interno: el punto de vista interno tendría una naturaleza puramente cognitiva, constituiría así una experiencia intelectual absolutamente compatible con cualquier actitud de la voluntad. En este caso, todos los sujetos dotados de un mínimo de información podrían adoptar un punto de vista interno; únicamente el aprendizaje de un lenguaje, el lenguaje de los aceptantes, sería condición necesaria de la adopción de un punto de vista interno.

La aceptación consistiría, por el contrario, en una actitud de la voluntad: la voluntad, como se ha sugerido, de conservar un cierto estado de cosas ${ }^{15}$. Aceptar una regla, actuando conforme a ella, contribuiría a su superviven-

${ }^{12}$ En este sentido R. Guastini (1997a), p. 431, sostiene que «aceptación y rechazo presuponen conocimiento de aquello que se acepta o refuta».

${ }^{13}$ Cfr. R. Sartorius (1987), p. 51.

${ }^{14}$ Cfr. V. Villa (1993), p. 268, sostiene que el conocimiento (que él llama de sentido común) del sentido de la norma «es (en ciertas condiciones) un presupuesto necesario de la aceptación de la norma, aceptación que es, a su vez, un presupuesto necesario para la existencia social de la regla misma», cfr. también p. 220, donde claramente se lee que «para aceptar es necesario conocer lo que se acepta». Se imponen dos observaciones: En primer lugar, es necesario evidenciar el hecho de que la categoría de los juristas tiene por definición un conocimiento que no es de sentido común, sino técnico, cualificado; V. Villa (1993), p. 338, añade de hecho que «se puede muy bien conocer la norma sin aceptarla en sentido pleno (como hacen los juristas y los teóricos del derecho) [...]». En segundo lugar, Hart, en la definición de punto de vista interno, hace referencia explícita a la aceptación y al uso de normas. Cfr. H.L.A. Hart (1961), p. 86, y M. Jori (1985), p. 131; V. Villa (1993), p. 338, define el uso social de la norma como «el conjunto de operaciones colectivas con las que una parte cualificada de miembros de una comunidad jurídica conoce, por medio de la interpretación, el contenido de la norma, la acepta como guía de la conducta, la aplica en todas las circunstancias de la vida cotidiana [...]». Cfr. también P.M.S. Hacker (1977), p. 16, según el cual la noción de usar una regla no es clara: «We might claim that rules are used when circumstances are recognized as operative facts for performance of a norm-act. But this too will not, in itself, distinguish acceptance from rejection».

${ }^{15}$ Cfr. N. Bobbio (1966). 
cia y a la globalidad del ordenamiento del que forma parte; aceptar la regla de reconocimiento, como ha sostenido Scarpelli, implicaría comprometerse en el plano valorativo con el sistema político existente.

Nos encontraríamos entonces con dos puntos de vista distintos, ambos internos, de los cuales sólamente uno presupondría la aceptación.

El problema, en efecto, es sobre todo terminológico; todo depende de la definición de derecho y de aceptación que se adopte. Se puede definir la aceptación de forma que sea compatible con una actitud no comprometida en el plano valorativo; se puede definir de modo que resulte independiente de la conformidad a la regla ${ }^{16}$; se puede adoptar la definición de Hart y tratar de hacerla compatible con las tesis teóricas fundamentales del positivismo; o bien se puede hacer como si el concepto de aceptación nunca hubiese sido introducido en la teoría del derecho y continuar usando un concepto austiniano, el de la obediencia habitual, que, aunque es menos sofisticado que el modelo hartiano de la aceptación, quizá tenga una mayor capacidad explicativa. Podríamos decir: explica menos, pero explica mejor.

Entre las propuestas de redefinición del concepto de aceptación me parece interesante la propuesta por Jori, que reduce la aceptación de normas «meramente descritas desde un punto de vista interno, a un acto intelectual de toma en consideración, que no implica la adopción de la norma como guía del propio comportamiento, sino sólo como criterio de juicio, en un sentido meramente intelectual, de tal comportamiento, en base a las normas jurídicas consideradas» ${ }^{17}$.

Tal definición parece traducir lo que Navarro y Redondo han llamado «actitud positiva» hacia la norma. Nada más, por tanto, que una toma en consideración. Una aceptación similar podría llamarse aceptación formal aunque no se corresponda con lo que desde Redondo ${ }^{18}$ se ha definido como

${ }^{16}$ Sobre el hecho de que la aceptación no se reduce a la conformidad existe además acuerdo. Cfr. F. Ost, M. van de Kerchove (1987), P.M. Hacker (1966), N. Bobbio (1966). Según F. Ost, M. van Kerchove (1987), la aceptación de una regla, de la cual el jurista debería apoderarse, se situaría en el nivel de las «representaciones» que han acompañado (precedido o seguido) al comportamiento del individuo. Hablando de representaciones se incurre obviamente en el peligro de ser acusado de psicologismo; estos autores, p. 33, responden anticipadamente a esta crítica recordando que por «representaciones» se entiende «l'echo produit, au plan individuel, par un ensemble de discours et de pratiques au sein duquel l'acteur du jeu social est imergé». R. Shiner (1992), habla de «mental accompaniements». Sobre el riesgo de exigir al jurista exageradas cualidades introspectivas, cfr. A. Catania (1987), p. 24-25.

${ }^{17}$ Cfr. M. Jori (1985), 132.

${ }^{18}$ Cfr. Redondo (1996), pp. 189-190, que llama «la regla lógica que permite introducir un contenido como premisa de un argumento: regla de suposición». Tal aceptación se conoce en cierta literatura, cfr. entre otros, J. Cohen (1992), como assumption. El término assumption puede ser traducido al italiano como «presupposizione» (de sonido exquisitamente jurídico), «assunzione». 
aceptación en sentido formal: el acto consistente en adoptar una norma como premisa de un argumento en sentido lógico ${ }^{19}$; este acto sería distinto del que consiste en adoptar una norma como razón para actuar.

Por tanto, se pueden sostener tres conceptos de aceptación: aceptación en sentido normativo; aceptación como reconocimiento intelectual, en sentido cognitivo; y aceptación como selección de premisas de un razonamiento, en sentido lógico.

Parecería oportuno dar nombres distintos a cosas fundamentalmente distintas. Se podría hacer fácilmente: aceptación, reconocimiento y asunción. Pero en lugar de esto prefiero subrayar que la naturaleza del acto de aceptación permanece en última instancia invariable; lo que cambia es su función en el ámbito del discurso en el que participa el aceptante. Aceptar, referido a reglas, puede entenderse como el acto de adoptar el modelo de conducta, en el sentido de regular la propia conducta sobre la base del modelo (¿seguir una regla?); o bien, en contextos teóricos, puede significar, más modestamente, admitir que un cierto modelo de conducta forma parte de lo calificado deónticamente por una norma o, mejor, por una formulación normativa (¿interpretación?); y también podría significar tomar la norma como una razón para actuar, junto con otras normas ya aceptadas, pero sin conformarse necesariamente a ella (¿retórica?). No creo que sea útil buscar una clasificación definitiva de los actos de aceptación. Lo necesario, y suficiente, es no ignorar la complejidad de las situaciones que, a veces apresuradamente, se explican en términos de aceptación.

\section{Puntos de vista y discursos del jurista}

De acuerdo con una interpretación ${ }^{20}$ de su pensamiento, para Hart el jurista no se situaría ni en una perspectiva completamente interna ni en una completamente externa. Hart ${ }^{21}$, quizá para dar cuenta al menos en parte de la figura del jurista, adoptando tal interpretación, ha sugerido la existencia de una tercera posición que ha sido definida como punto de vista externo

${ }^{19}$ Este sentido de aceptación puede ser criticado, no en sí mismo, sino como interpretación imposible del pensamiento de Hart. Cfr. A. catania (1987), p. 25, nota, quien, basándose en la clara contraposición presente en la obra de Hart (p. 88) entre «el punto de vista de aquellos que aceptan las normas y el punto de vista de aquellos que las rechazan» excluye que la aceptación pueda ser entendida en sentido formal. El mismo Hart, cfr. H.L.A. Hart (1983), p. 167, además, ha atenuado la relación entre aceptación de la regla de reconocimiento y enunciados internos, dado que ha sostenido que -como ha hecho notar J.C. Bayón (1991), pp 2526- con los enunciados internos sobre la validez de una norma jurídica «se manifiesta normalmente la aceptación por parte de quien habla de la regla de reconocimiento del sistema».

${ }^{20}$ Cfr. N. MacCormick (1981), pp. 34-40.

${ }^{21}$ Cfr. H. L. A. Hart (1983), p. 14; en efecto, como recuerda M. Barberis (1990), p. 297, Hart parece haberse limitado a ratificar la corrección propuesta por MacCormick. 
moderado o no extremo. Esta sería la posición del observador que suspende su propia adhesión a los fenómenos normativos que observa y, aun así, no deja de dar cuenta del modo en que los actores de la escena jurídica consideran las normas desde un punto de vista interno.

Algunos autores, y pienso sobre todo en MacCormick, han retomado esta categoría hartiana refiriéndose al punto de vista externo moderado como punto de vista hermenéutico ${ }^{22}$.

Este punto de vista, en opinión de MacCormick, requiere, por un lado, el total acuerdo con el elemento cognitivo del punto de vista interno y, por otro lado, la plena percepción y comprensión del elemento volitivo, aunque no acompañadas del acuerdo, esto es, no acompañadas de una preferencia por el modelo de conducta por lo demás percibido en su autenticidad ${ }^{23}$.

La relación entre el punto de vista interno y el punto de vista hermenéutico es estrecha. El segundo presupone el primero; el segundo puede ser adoptado sólo si el primero es como mínimo tomado como hipótesis o postulado.

${ }^{22}$ Cfr. N. MacCormick (1981), pp. 34-40, en particular p. 37, donde define el punto de vista externo moderado, es decir, el punto de vista hermenéutico: «To be an "outsider" in this sense is neither necessarily to be a member nor necessarily to be a non-member of the group governed by those legal rules [...]. It is simply to hold apart questions of one's own commitments, critical morality, group membership or non-membership, in order to attend strictly to the task of the descriptive legal or social theorist [...]»; y p. 39, donde pone de manifiesto la función de la aproximación hermenéutica en la explicación e interpretación de tradiciones y textos religiosos. Cfr. también N. MacCormick (1982), par. 3, y P.M. Hacker (1977), pp. 17-18, quien atribuye a Hart el mérito de haber sido el primer positivista que ha adoptado un método hermenéutico que permite comprender el significado de las conexiones normativas: «[...] a description of the behaviour governed by the rule which will render the behaviour intelligible must involve reference to the normative situation as apprehended by the agents and members of the group».

${ }^{23}$ N. MacCormick (1981), p. 39: «(a) full sharing in the cognitive element of internal point of view [...] and (b) full appreciation of, but no cecessary sharing in, the volitional element, the will or preference for conformity to the pattern as a standard». Esta aparente solución desplaza en efecto el problema. Consideremos el ejemplo de un teórico que emite un enunciado en términos de legitimidad constitucional; está claro que sabe qué es una norma inconstitucional, porque ya ha emitido millares de enunciados de ese tipo y ha observado millares de veces situaciones en los cuales los problemas de constitucionalidad eran solventados y resueltos. Podemos decir que su enunciado es comprensible, que puede ser legítimamente pronunciado. Pero -y aquí se encuentra el verdadero problema- ¿en qué elementos podemos basarnos para sostener que tal enunciado describe una situación existente, una realidad jurídica? En efecto, esta observación está en la base de la crítica que sostiene la imposibilidad de un punto de vista hermenéutico que capte el sentido que tienen para los agentes los hechos jurídicos, caracterizando el universo jurídico de una comunidad. Así, si dos teóricos del derecho, pertenecientes a la misma comunidad jurídica estatal y a la misma corriente filosófica, emitieran dos enunciados contradictorios en términos de legitimidad constitucional tendríamos necesariamente que desacreditar la verdad de uno de los dos; el problema es: ¿con qué criterio? Dejo por ahora abierta la cuestión; os responderé implícitamente en seguida. 
El propio MacCormick ${ }^{24}$ ha sostenido que el teórico del derecho puede profundizar en algunos fenómenos sociales, comprenderlos, sin por ello verse comprometido. Es más fácil estar de acuerdo con esta afirmación cuanto más vago se mantiene el significado de comprender y verse comprometido $^{25}$. MacCormick habla de la humanidad del teórico; pues bien, el hecho de que el teórico sea un ser humano, el hecho de que sea capaz de comprometerse moralmente, de tener una ideología, de reconocer autoridad, le permite saber cuándo un sujeto reconoce cierta autoridad, acepta una norma, etc. El teórico es por tanto externo respecto de la práctica de los aceptantes, respecto de los miembros de una comunidad jurídica particular, pero es interno en al menos dos comunidades, y por ello se sitúa en una perspectiva interna en al menos dos sentidos: en el sentido de que, en cuanto ser humano, pertenece a una comunidad jurídica y, en cuanto teórico, pertenece a una comunidad científica, lo que requiere un cierto bagaje de conocimientos y un cierto vocabulario ${ }^{26}$.

Se ha sostenido, en contraste con la tesis que he atribuido a MacCormick, que el jurista «institucional», la doctrina en sentido estricto, no pue-

${ }^{24}$ Cfr. N. MacCormick (1982), par. 3.

${ }^{25}$ Merece tratarse con profundidad la posición de MacCormick -que, continuando en el ámbito de la teoría hartiana, parece muy interesante y discutible- según la cual el teórico del derecho debería ser un practicante de la hermenéutica; debería ocuparse del estudio y la interpretación de los hechos tal y como son vistos y percibidos por los agentes; de esta manera, el teórico llegaría a reconstruir la relación entre el comportamiento consistente en observar una norma y las actitudes que los observantes asumen sobre la base de los valores a los que se adhieren. La posición de MacCormick parece plausible, pero la corrección a la teoría hartiana que propone ha sido criticada. Jori, en efecto, ha sostenido que, respecto a la solución encontrada, MacCormick acierta en parte, pero se equivoca en otra. Según Jori, la solución de MacCormick, aparentemente simple y coherente, es sin embargo simplista, porque no tiene en cuenta el hecho de que en realidad los discursos de los juristas se asemejan a los «discursos que constituyen uso de las normas jurídicas», al discurso interno hartiano de quien acepta el derecho. Los errores de Hart serían así más fértiles que la aparente solución de MacCormick, quien, simplemente, desconoce la peculiaridad de la actividad de la ciencia jurídica y del método jurídico. Cfr. M. Jori (1985), pp. 223-224, 227-228 y 232, donde Jori señala que, sin embargo, la corrección de MacCormick salvaría a la teoría de Hart de la crítica de Scarpelli (cfr. U. Scarpelli (1965) y (1982)).

${ }^{26}$ Obviamente, la afirmación según la cual el teórico pertenece a una comunidad científica, como recuerdan F. Ost y M. van Kerchove (1993), ensayando la posibilidad de aplicar el concepto kuhniano de paradigma a la ciencia jurídica, es cualquier cosa menos problemática. Por el contrario, Aulis Aarnio (1987), cap. 3, quizá ayudado por la familiaridad con el universo de la ciencia jurídica finlandesa (sobre la influencia de la cultura jurídica escandinava en el optimismo de Aarnio, cfr. P. Comanducci (1994)), aplica sin problemas a la dogmática jurídica el concepto kuhniano de matriz. Sin referencia a Kuhn, M. Jori (1985), pp. 135-136, interpretando lo que Hart llama «general framework of legal thought» en el prefacio de The Concept of Law, se refiere a «normas sobre el 'funcionamiento' del pensamiento jurídico (en particular el de los juristas) [...], normas metodológicas y lingüísticas [...]». También N. MacCormick (1982), par. 3, subraya que el teórico es externo a cualquier práctica, excepto a la de hacer teoría, que como las otras está gobernada por reglas. 
de más que pronunciar enunciados internos comprometidos. Como es sabido, esta es la tesis de Scarpelli, según la cual la ciencia jurídica positivista no se limita a «describir la actitud consistente en asumir la norma como guía del comportamiento y criterio para juzgar», sino que la expresa y la ejercita mediante «un discurso orientado al conocimiento de las normas y a la cualificación de los comportamientos según sus relaciones con las normas» ${ }^{27}$.

Si se plantea el problema de la naturaleza de los enunciados con los que los juristas describen el derecho, la atención se desplaza de la distinción entre puntos de vista a la distinción entre diferentes tipos de discurso ${ }^{28}$.

Hart ha distinguido entre internal y external statements ${ }^{29}$; MacCormick adopta la expresión normative statements; estos últimos, que se corresponden con los enunciados internos ${ }^{30}$ de Hart, pueden ser emitidos desde un punto de vista interno o desde un punto de vista hermenéutico ${ }^{31}$. Esto implica que los enunciados con los cuales los juristas describen el derecho tienen la misma forma que los enunciados de los aceptantes ${ }^{32}$.

No plantean problemas y pueden ser dejados de lado los enunciados emitidos desde el punto de vista interno moderado por una sociología jurídica adecuada que no incurra en ningún reduccionismo ${ }^{33}$.

${ }^{27}$ U. Scarpelli (1965), pp. 66-67. Para una reciente y puntual reconstrucción crítica del pensamiento de Scarpelli sobre este punto, cfr. R. Guastini (1997a).

${ }^{28}$ Cfr. G. Tarello (1974), par. 2, según el cual se puede distinguir entre los discursos asertivos y los prescriptivos de acuerdo con tres criterios: la forma gramatical o estilo, el significado, la función particular o «fuerza»; esto es equivalente a distinguir el nivel de los enunciados, de las proposiciones y de las enunciaciones.

${ }^{29}$ Cfr. H. L. A. Hart (1961), p. 99, donde los enunciados internos son caracterizados como aquellos que manifiestan el punto de vista interno y son usados naturalmente por aquellos que, aceptando la regla de reconocimiento, la aplican, reconociendo las normas singulares del sistema como válidas.

${ }^{30}$ Para ser completos, es necesario decir que «statement» ha sido traducido como «asserzione» o como «affermazione».

${ }^{31}$ N. MacCormick (1981), p. 39: «Any such normative statement may be made either from the internal point of view or from the hermeneutic point of view, and the mere act of making such a statement is entirely ambiguous in its presuppositions as between the two».

${ }^{32}$ No se entiende por qué MacCormick no ha sostenido que desde el punto de vista hermenéutico se emiten enunciados «interpretativos» o algo de este tipo. Cfr. M. Barberis (1990), p. 298: «tanto si se encuentra ante una regla no formulada [...] como si se encuentra ante una regla formulada [...] la doctrina no describirá plenamente, en sentido propio, sino que más bien interpretará».

${ }^{33}$ Estos enunciados serían emitidos aparentemente desde el mismo punto de vista hermenéutico, pero, como ha sido brillantemente subrayado (cfr. J.C. Bayón (1991), p. 27-28), no versarían sobre el mismo objeto: el jurista hermenéutico da cuenta del derecho, emite enunciados en un lenguaje normativo, aclara el sentido -dentro de los límites en los cuales se le concede acceso a dicho sentido- de la realidad jurídica; mientras que el jurista sociólogo se plantea los hechos, siempre conectados con la realidad del derecho, pero pertenecientes a la reali- 
Como ya se ha señalado, Hart también ha corregido su posición acerca de los tipos de discurso: dos tipos de enunciados, comprometidos (committed) y distanciados (detached), pueden expresar la adopción de un punto de vista interno ${ }^{34}$. Los primeros son emitidos por quienes aceptan las normas, y los segundos son emitidos por quienes hablan como si hubiesen aceptado las normas, pero en realidad no tienen ningún compromiso a favor de esas mismas normas.

Los enunciados internos distanciados se parecen mucho a aquellos condicionales que, siguiendo un ejemplo de Alchourrón y Bulygin ${ }^{35}$, afirman que algo sería debido (o estaría permitido) si la norma fundamental fuese válida o, en otros términos, si se aceptara la obligatoriedad del principio fundamental. No hablo de regla de reconocimiento porque, en la medida en que no se considera una genuina norma de conducta, y ni siquiera una norma de conducta no genuina, no tiene sentido hablar de su obligatoriedad.

Según algunos ${ }^{36}$, estos enunciados normativos no comprometidos, aunque no dejen de ser normativos, podrían ser verdaderos o falsos; para explicar esta aparente contradicción se puede entender «normativo» en el sentido formal de «formulado en el lenguaje normativo» ${ }^{37}$.

La distinción entre comprometido y distanciado parece así justificada por la exigencia de hacer compatibles la adopción del punto de vista inter-

dad social en su complejidad; sus enunciados serán verdaderos o falsos. Como señala U. Scarpelli (1965), p. 55, «la sociología como ciencia empírica [...] tiene como acto constitutivo la adopción del punto de vista externo», y su discurso descriptivo, lejos de reducirse al del antropólogo, incluirá «la descripción de las actitudes de los miembros del grupo hacia las normas y la referencia a los conceptos que expresan tales actitudes».

${ }^{34}$ Cfr. H. L. A. Hart (1983), p. 14 y H. L. A. Hart (1982), pp. 153-155.

${ }^{35}$ C.E. Alchourrón - E. Bulygin (1981).

${ }^{36}$ Para un cuidadoso análisis de esta posición raziana, aparentemente contradictoria, cfr. C.E. Alchourrón - E. Bulygin (1981), donde se critica la posición sostenida por J. Raz (1981).

${ }^{37}$ En este sentido encontramos la distinción entre enunciados deónticos prescriptivos y enunciados deónticos descriptivos propuesta por A.G. Conte (1985), quien, por otro lado, no se ocupa, o mejor no profundiza en ese lugar, en nuestro problema: «es descriptivo un enunciado deóntico usado por un jurista». Por otro lado, Conte, lejos de ignorar el problema del estatuto de los enunciados deónticos de la ciencia jurídica, prefiere atribuir a tales enunciados las categorías de validez e invalidez, y no los comprometedores verdad y falsedad, como hace Raz. Por exigencias de coordinación, tengo que precisar que los enunciados normativos descriptivos serían en el lenguaje de MacCormick -en este sentido, al menos, J.C. Bayón (1991)- los enunciados que el teórico pronuncia desde el punto de vista hermenéutico. Desde un punto de vista terminológico existe todavía una dificultad, por lo demás fácilmente superable: el punto de vista hermenéutico de MacCormick correspondía al punto de vista externo moderado de Hart y, precisamente por ser externo, conservaba su cualidad de ser descriptivo; mientras que los enunciados distanciados presuponen y expresan el punto de vista interno, aunque no la aceptación. Lo cierto es que se encuentra entre los dos extremos. Sin embargo, sería conveniente establecer si el punto de vista hermenéutico y los enunciados no comprometidos merecen o no la propiedad de internos. 
no con una actitud distinta de la del aceptante. Esta exigencia adquiere relevancia sólo si se entiende la aceptación en sentido fuerte, es decir, si se le atribuye al acto de aceptación un carácter moral.

Los enunciados distanciados y los enunciados comprometidos se corresponderían, por tanto, con los dos tipos de punto de vista interno tal como antes se han distinguido. Los enunciados distanciados son emitidos por aquellos que no aceptan las normas. Por el contrario, los enunciados comprometidos manifiestan la aceptación en sentido fuerte de las normas.

Prescindiendo del hecho de que se consideren como enunciados internos distanciados ${ }^{38} \mathrm{o}$ como enunciados condicionales, los enunciados que predican la validez de una norma son los típicos del jurista que, utilizando ciertos criterios de validez, comprueba (o decide: esto es otro problema) que la norma satisface tales criterios. Se puede sostener que este tipo de enunciados es interno, pero no que sea prescriptivo. Es importante, por tanto, tener en consideración este tipo de enunciados, porque su existencia podría suscitar dudas sobre la ecuación interno $=$ prescriptivo y externo $=$ descriptivo. Decir que una norma no es válida no tiene -por lo menos al margen de circunstancias excepcionales- función prescriptiva. Sin embargo, si miramos en un nivel superior, se puede decir con Hart que, emitiendo un enunciado de este tipo, se acepta una regla de reconocimiento como guía para la identificación de las normas válidas y se propone esta guía a otros juristas y a los operadores jurídicos. Enfrentaré en seguida este aspecto del problema; lo que es necesario destacar es que un juicio de validez se sitúa en el interior del sistema jurídico: de un lado, no tiene pretensiones en cuanto a la aplicación del Derecho; de otro, no incide necesariamente sobre los criterios de validez. Los juicios de validez son enunciados internos respecto del sistema del que extraen los criterios y enunciados externos respecto de las normas de las que predican la validez.

Antes de profundizar en la naturaleza de la regla de reconocimiento ${ }^{39} \mathrm{y}$ la pluralidad de objetos sobre los que pueden versar los enunciados de los

${ }^{38}$ Por lo que respecta a la distinción entre enunciados distanciados y enunciados comprometidos ya se ha dicho que, si por compromiso se entiende -como parece hacer Raz- «compromiso moral», podemos olvidarla. Si por el contrario con ella se quiere dar cuenta del hecho de que se puede expresar un juicio de validez sin pronunciarse sobre la obligatoriedad de las normas consideradas válidas, la podemos igualmente olvidar, porque confunde más que lo que explica. En efecto, esta distinción tiene sentido si se aplica a una teoría, como la kelseniana, que identifica validez y obligatoriedad. Al no asentarse sobre terreno firme, se impone el olvido de esta distinción.

${ }^{39}$ La literatura sobre la regla de reconocimiento ya se ha extinguido. Aparte de las obras de Hart ya citadas, hay que señalar J. Páramo Argüelles (1984), J. Ramos Pascua (1989), R. Caracciolo (1991). Para un reciente repaso de las tentativas de identificación de la regla de reconocimiento cfr. M. Atienza, J. Ruiz Manero (1996), pp. 150 y ss. Sobre la posibilidad de una pluralidad de normas de reconocimiento, cfr. M. Jori (1985), pp. 147-149. 
juristas, merece ser recordada la observación de Guastini ${ }^{40}$ según la cual utilizando expresiones como «principio fundamental» o «regla de reconocimiento» mismo se hace referencia, indistintamente, al menos a tres cosas distintas (produciéndose de esta manera fáciles confusiones conceptuales): a un criterio de validez, al conjunto de las normas sobre la producción jurídica, y a una norma moral que impone obedecer a las normas válidas.

Quiero además recordar, también sin profundizar, la tesis que considera la regla de reconocimiento no como una norma de conducta, sino como una regla conceptual ${ }^{41}$, y las varias tesis que intentan hacer depender la existencia de tales reglas de la actividad del juez y, para evitar la circularidad del argumento, recurren a reglas morales o prácticas sociales para la identificación de los jueces ${ }^{42}$.

No profundizaré más en el debate porque me parece claro que la regla de reconocimiento no es una genuina norma de conducta ${ }^{43}$ y también me parece claro que los jueces vienen identificados en base a ella. En efecto, es la ciencia jurídica la que, «con la asunción del punto de vista interno» procede «a la determinación de los criterios por los cuales ciertas normas puestas por la voluntad de seres humanos vienen identificadas como normas del derecho positivo y por ello son tomadas como guía del comportamiento y criterio para juzgar y son tenidas en cuenta en la práctica» ${ }^{44}$.

${ }^{40}$ R. Guastini (1997a), p. 423.

${ }^{41}$ Para un interesante enfrentamiento amigable sobre la cuestión «regla de conducta/regla conceptual», cfr. E. Bulygin (1976), (1991a), (1991b) y J. Ruiz Manero (1990), (1991).

${ }^{42}$ Cfr. N. MacCormick (1981) y C. Nino (1985).

${ }^{43} \mathrm{Me}$ limito a hacer una modesta crítica a propósito del modo, a veces demasiado apresurado, con el que se decreta que las definiciones no tienen carácter normativo. En efecto, allí donde una definición es la única razón para que exista la exigencia de hacer funcionar un sistema de genuinas reglas de conducta, me parece legítimo sostener su carácter transitivamente normativo. Con excesiva rapidez se equipara la regla de reconocimiento, entendida como regla conceptual, como definición de validez, a una regla gramatical o a una regla de juego. Creo que aunque el derecho sea lenguaje y juego, no se puede olvidar que no todos los conceptos tienen el mismo valor y que no todas las definiciones tienen la misma fuerza. Sobre la distinción entre normas y definiciones, de un modo más exhaustivo, C.E. Alchourrón - E. Bulygin (1982).

${ }^{44}$ U. Scarpelli (1965), p. 58. También parece de acuerdo con este punto J. Raz (1980), cap. VIII, quien, citando expresamente donde Hart argumenta a favor de la adopción de su doctrina de la regla de reconocimiento, observa algo que a mi entender es fundamental: para responder a la cuestión de la existencia de una disposición en un sistema jurídico dado, se necesita hacer referencia no a otra disposición, sino a un criterio doctrinal. También Raz, como Jori, se plantea la posibilidad de más reglas de reconocimiento y subraya que, en el caso de la regla de reconocimiento la única reacción crítica a la desviación que puede producir un efecto cualquiera es la de la doctrina. Sobre este punto véase también el reciente análisis de R. Guastini (1997a), en particular pp. 424 y ss. (que, a mi entender, debidamente interpretada, supera el problema de la pluralidad de normas de reconocimiento), donde sostiene que en muchos ordenamientos, por ejemplo, en el italiano, no existe un criterio general de validez que esté for- 
Esta afirmación de Scarpelli prepara el terreno para la reformulación de mi tesis.

Los juristas, con los juicios de validez, no describen normas. Sin embargo, tampoco prescriben a cualquiera su obligatoriedad. No se encuentran ante un objeto que pueda describirse, sino ante un conjunto de materiales de naturaleza más o menos directamente lingüística, preparados para ser modelados según las formas jurídicas y sucesivamente sistematizados. Para llevar a cabo esta operación aceptan algunas reglas, que corresponden a lo que genéricamente puede llamarse principio fundamental.

En efecto, con la regla de reconocimiento, que Scarpelli prefiere llamar principio fundamental, los juristas se sitúan en un nivel de discurso superior: el discurso con el cual la ciencia jurídica elabora el criterio para la identificación de las normas del sistema es «un discurso normativo en el nivel metalingüístico» ${ }^{45}$.

La distinción entre varios niveles del lenguaje nos obliga a distinguir entre tres niveles de descripciones posibles; resultará que existen tantas parejas de puntos de vista como posibles niveles de discurso.

\section{Actores y contextos del discurso jurídico}

En relación con la diversidad de los tipos de juristas es interesante el análisis realizado por M. van Kerchove y F. Ost ${ }^{46}$, que distinguen diferentes puntos de vista de acuerdo con las diversas funciones ${ }^{47}$-muchas veces rea-

mulado, positivo, añado yo, y los juristas obtienen, a partir de una reconstrucción de los criterios particulares de invalidez de las normas (de todos los niveles), un criterio de validez, «un macro-criterio (general) de validez: un "principio fundamental", en el léxico de Scarpelli». Me pregunto si , en caso de que este macro-criterio fuese formulado, los teóricos del derecho se limitarían a usarlo o bien, como propendo a pensar, lo reconstruirían, para afinarlo, con el resultado concreto de restar influencia al dato positivo. Según Guastini son igualmente los juristas, «o más bien: los teóricos del derecho», los que extraen, del conjunto de normas que en cierto sentido prescriben la obediencia al derecho, «la macro-norma 'iterativa' según la cual las normas válidas deben ser obedecidas [...]».

${ }^{45}$ U. Scarpelli (1965), p. 81: el principio fundamental es considerado una proposición en el nivel metalingüístico. Para R. Guastini (1997a), p. 410, el principio fundamental de Scarpelli corresponde a la norma fundamental de Kelsen.

${ }^{46}$ Cfr. F. Ost, M. van Kerchove (1987), pp. 43-51. los autores se sirven de una metáfora del contexto teatral, que les permite hablar de «actores de la escena jurídica», de «espectadores», etc. Hay que destacar que recientemente la distinción entre punto de vista interno y punto de vista externo ha sido criticada y en su sustitución se ha propuesto, probablemente debido a la utilización de una metáfora lúdico-deportiva, la distinción entre participantes y observadores. Para la utilización de esta última distinción, cfr. entre otros J. C. Bayón (1996), A. Calsamiglia (1996).

${ }_{47}$ También está basada en la distinción entre niveles de generalidad la clasificación realizada por V. Villa (1993), pp. 272-287, según la cual, cuando se habla de ciencia jurídica nos podemos estar refiriendo a la jurisprudencia, a la teoría general del derecho o a la teoría del derecho. Por lo que se refiere a las diferentes actividades desarrolladas por los juristas, cfr. G. Ta- 
lizadas por los mismos individuos- que pueden encontrarse en la ciencia jurídica ${ }^{48}$.

En pocas palabras, utilizando como criterio para la distinción la teoría de los niveles del lenguaje, se puede sostener que los teóricos belgas individualizan al menos cinco niveles de descripciones y análisis que se pueden distinguir estipulando nombres diversos para los autores de los diferentes discursos: la doctrina, desde un punto de vista interno, trata de influir en los otros operadores jurídicos (en los jueces en particular), proponiendo interpretaciones ${ }^{49}$; la dogmática jurídica sistematiza las normas, producto de la interpretación, sin participar por ello en alguna actividad en algún sentido normativa, y quedando así absolutamente como espectadora ${ }^{50}$; la ciencia ju-

rello (1980), pp. 24-33, donde, enumerando las razones para rechazar la creencia de que «todo el derecho procede exclusivamente de todas las leyes», habla de interpretación de la ley, de integración de la ley, de estudio del derecho y de individualización de la norma. En el mismo sentido, M. Barberis (1990), pp. 299-301, quien distingue tres grandes sectores de actividad: la interpretación en sentido estricto, la integración y la sistematización del derecho.

${ }^{48}$ La tipología elaborada por Van de Kerchove y F. Ost está claramente más articulada que la elaborada por Hart, el cual, como es sabido, no se ocupó, probablemente por razones históricas, de la posición ocupada por el teórico del derecho y el jurista práctico: «la aplicación del derecho por parte del jurista, más que el conocimiento y descripción por parte de la doctrina, tiene una importancia central en la teoría hartiana del derecho». Otra de las razones históricas, señalada por M. Jori (1985), p. 130, es el «hecho histórico y sociológico de que el llamado científico del derecho, estudioso de la llamada doctrina jurídica (esto es, en última instancia, el profesor universitario de derecho que escribe libros sobre el derecho), ha tenido históricamente y tiene actualmente una importancia bastante menor en el mundo anglosajón que la que ha tenido y tiene en el continente europeo»; la justificación del desinterés de la literatura anglosajona por el problema de la cientificidad de la actividad del jurista puede estribar también en razones lingüísticas: en efecto, como recuerda M. Barberis (1990), p. 302, en lengua inglesa el término «science» designa solo la ciencia de la naturaleza, por lo que el problema de la cientificidad de la «jurisprudencia», simplemente, no tiene sentido. El problema, más bien, viene expresado en términos de conocimiento jurídico, lo que, a decir verdad, no reduce su importancia.

${ }^{49}$ F. Ost, M. van de Kerchove (1987), pp. 45-46: se trata del punto de vista interno científico (savant), de la doctrina en sentido estricto, que, en su labor de definición, clasificación y sistematización, se permite tomar posición a favor o en contra de algunas interpretaciones de la jurisprudencia. Según los autores, este punto de vista denota la naturaleza híbrida de la actividad doctrinal, porque, en cuanto interna, comporta la aceptación de las normas y, en cuanto científica, comporta una actitud distanciada respecto del objeto de estudio. Este punto de vista parece ser el de aquella que A. Aarnio (1987), cap. 1, llama dogmática práctica, caracterizada por la combinación de dos elementos: de un lado, encuentra su razón de ser en la práctica jurídica; de otro, está impregnada de una actitud científica. Utilizando un método científico, realiza una actitud de purificación de los prejuicios que normalmente existen en la práctica jurídica normal. La interpretaciones que propone son verificables mejor que las que realizan por ejemplo los abogados y es por esto que produce mejores resultados respecto de la verdad acerca del ordenamiento. Su orientación pragmática la contrapone a la dogmática teórica, interesada más bien en la coordinación sistemática del ordenamiento. Para Aarnio, estos puntos de vista son epistemológicamente internos pero, a diferencia del punto de vista del juez, funcionalmente externos.

${ }^{50}$ F. Ost, M. van de Kerchove (1987), pp. 44-45: se trata del punto de vista descriptivo, que da cuenta del punto de vista interno de los participantes en el derecho; es el punto de vis- 
rídica reconstruye y explica la normatividad de las instituciones jurídicas que caracterizan a los sistemas jurídicos, así como las reformulaciones de la dogmática $^{51}$; la teoría general del derecho revela y reconstruye las propiedades y el funcionamiento de los ordenamientos jurídicos y del método de la ciencia jurídica ${ }^{52}$; la filosofía del derecho (analítica y hermenéutica) analiza los fundamentos implícitos de las teorías generales del derecho y las critica a la luz de una filosofía general ${ }^{53}$.

Simplificando un tanto, se puede decir que cada discurso versa sobre el precedente y que, por ello, el discurso de los filósofos del derecho de ca-

ta de la dogmática jurídica cuando desarrolla la función de sistematización de un ordenamiento jurídico particular; la adopción de este punto de vista, puramente externo, es típico de aquellos que efectúan estudios de derecho comparado o de historia del derecho; se puede pensar que un jurista italiano que analiza el derecho penal japonés no tiene ninguna intención creadora y política, y que se limita realmente a una reconstrucción de lo que para los funcionarios y ciudadanos japoneses constituye el derecho válido japonés. A. Catania (1987), p. 38, hace referencia a la actividad de aquellos estudiosos que «encontrándose en la situación de no ser destinatarios del ordenamiento jurídico, porque, por ejemplo, son de distinta nacionalidad, analizan el comportamiento [...] de los obligados por las normas».

${ }^{51}$ F. Ost, M. van de Kerchove (1987), pp. 49-50: se trata del punto de vista externo explicativo de la ciencia jurídica, ideal para los autores que, aun manteniendo la ruptura epistemológica respecto al objeto, necesaria para la cientificidad, no dejan de lado las representaciones de los actores de la escena jurídica. Esta categoría suscita problemas, en la medida en que no está claro cómo se puede penetrar, permaneciendo en un punto de vista externo, en las representaciones de los actores jurídicos. El problema es doble: en primer lugar, no es cierto que se pueda aprehender desde el exterior el sentido que tiene el derecho para los actores de la escena jurídica; y, en segundo lugar, aunque una descripción desde el exterior fuera posible, no es cierto que el derecho descrito desde el exterior coincida con el derecho descrito desde el interior. Sobre el primer punto, cfr. R. Shiner (1992); sobre el segundo J.C. Bayón (1996); para una crítica a la tesis de Bayón, cfr. P. Chiassoni (1996).

${ }^{52}$ F. Ost, M. van de Kerchove (1987), pp. 48-49: es el punto de vista externo analítico de la teoría general del derecho que analiza las propiedades de los ordenamientos jurídicos en general. En relación con esta categoría, los autores se preguntan si esta actitud aparentemente externa no trasluce a veces una cierta condescendencia hacia algún estado de cosas relacionado con la práctica de aquellos que adoptan un punto de vista interno. La teoría de Hart pertenece a esta categoría y, como sostiene M. Jori (1985), pp. 127-128, puede comportar la ambigüedad de confundir «el hecho de que las ideas o descripciones o explicaciones son difusas, con la bondad (según cualquier criterio) de las ideas o descripciones o explicaciones mismas». Ost y van de Kerchove mencionan también el punto de vista externo reductivo de aquellas teorías del derecho que, adoptando un punto de vista radicalmente externo, renuncian incluso a la tentativa de explicar el punto de vista interno de los participantes en el ordenamiento jurídico, reduciendo así, desde una perspectiva científica, el derecho a comportamiento observable (realismo jurídico) o traduciendo el fenómeno jurídico en términos económicos (teoría marxista). Para un profundo análisis del componente ideológico que acompaña la descripción del derecho, cfr. también M. Jori (1985), pp. 227 y 232-233 y U. Scarpelli (1982), pp. 184 y ss. y U. Scarpelli (1965), pp. 56 y ss.

${ }_{53}$ F. Ost, M. van de Kerchove (1987), pp. 50-51: es el punto de vista externo crítico, adoptado por estos autores (a su juicio), que da cuenta, desde un punto de vista externo, del punto de vista externo de los teóricos del derecho, desvelando las eventuales impurezas y deslizamientos hacia un punto de vista interno. 
rácter analítico y/o hermenéutico constituye un metalenguaje de quinto grado.

Como complemento de esta tipología es útil reclamar una ulterior distinción, que no es tratada por los autores belgas y que suele ser sobrevalorada por aquellos que defienden su existencia: la distinción entre teoría general del derecho y teoría del derecho ${ }^{54}$.

La teoría general del derecho se ocuparía de la individualización de las «nociones comunes a las diversas ramas de un ordenamiento jurídico particular», mientras que la teoría del derecho (que corresponde a la analytical jurisprudence inglesa) tendría como objeto de estudio las nociones más generales del derecho positivo, entre las cuales se pueden señalar las de «ordenamiento jurídico»y «validez» ${ }^{55}$.

Según esto, en mi opinión se puede introducir un ulterior nivel, entre la filosofía del derecho y la teoría general, representado por los estudios de la teoría del derecho, cuyo fin principal es la elaboración de un concepto de derecho que sirva «de punto de referencia normativo para todas las investigaciones desarrolladas por las otras disciplinas jurídicas» de nivel, obviamente, inferior ${ }^{56}$.

Por lo que se refiere a los contextos posibles del conocimiento jurídico y los objetos describibles en cada uno de ellos, algunos datos parecen incontestables: en efecto, es generalmente aceptada la distinción entre disposición y norma; igualmente es aceptada la distinción entre mero conjunto de normas y sistema de normas; se distingue, por último, entre sistema de normas, o sistema jurídico, y ordenamiento jurídico, entendiendo este último como el conjunto de sistemas jurídicos sucesivos ${ }^{57}$.

Nos encontramos en este punto con cuatro discursos posibles: acerca de las disposiciones, acerca de las normas, acerca de los sistemas y acerca de los ordenamientos. Siguiendo algunas sugerencias, propongo introducir dos objetos más: los micro-sistemas de normas ${ }^{58}$ y el ordenamiento estatal, entendido como sucesión de ordenamientos jurídicos ${ }^{59}$.

${ }^{54}$ Cfr. V. Villa (1993), pp. 282-287.

${ }_{55}$ Cfr. V. Villa (1993), p. 285. Obviamente, no está de acuerdo R. Guastini (1997a), p. 422, nota, donde habla de «nociones teórico-generales» como nociones «válidas para todos los ordenamientos positivos». Sin embargo, no importa quién tiene razón o qué clasificación es mejor: emotivamente comparto la definición de Guastini pero, por razones técnicas, me sirvo de la distinción trazada por Villa.

${ }^{56}$ Cfr. V. Villa (1993), p. 286.

${ }^{57}$ Sobre todo esto remito a C. Alchourrón - E. Bulygin (1971), E. Bulygin (1991a), (1983), R. Caracciolo (1988).

${ }^{58}$ Como recientemente ha recordado R. Guastini (1997b), pp. 69-70, el mérito de esta distinción corresponde a C. Alchourrón - E. Bulygin (1971), y a E. Bulygin (1983), que responde a algunas críticas formuladas a Normative System.

${ }^{59}$ Cfr. J. M Vilajosana (1997), pp. 222-223. 
En términos de pertenencia, todo esto se podría resumir como sigue: una disposición jurídica pertenece al conjunto de los documentos prima facie jurídicos; una norma pertenece a (el conjunto de posibles resultados de la interpretación de) una (o más) disposiciones jurídicas ${ }^{60}$; una norma pertenece a un micro-sistema jurídico que pertenece a un sistema jurídico que pertenece a un ordenamiento jurídico que pertenece a un ordenamiento estatal $^{61}$.

Tendremos entonces tantos criterios de pertenencia como relaciones de pertenencia descubiertas. En particular, el criterio de pertenencia más importante y delicado es el que permite establecer si dos ordenamientos jurídicos pertenecen al mismo ordenamiento estatal ${ }^{62}$.

La importancia del ordenamiento estatal se vuelve evidente cuando se considera la estructura de los modernos estados constitucionales.

La existencia de una constitución aumenta la complejidad del trabajo de los juristas; junto al juicio que decreta la pertenencia de una norma a un micro-sistema de normas (la norma que impone pagar una cierta tasa pertenece en el momento $t$ al derecho tributario), se puede formular el juicio que decreta la conformidad de la norma a los principios constitucionales. Sin embargo, se puede admitir que ese juicio está incluido en el juicio de validez.

El problema, la novedad, está constituida por el juicio en base al cual se considera que una ley constitucional pertenece al mismo ordenamiento estatal o por el juicio en base al cual, por el contrario, se considera que un cambio de la norma sobre reforma constitucional constituye el momento final, la muerte, de un ordenamiento estatal.

Recordar que el problema existe implica para mí justificar la necesidad de referir mi análisis a estados constitucionales. Me limitaré a señalar que, de un lado, la evolución de los estados contemporáneos está abocada a so-

${ }^{60}$ Dejo de lado por poco importante en este contexto el hecho de que la relación entre disposiciones y normas sea más compleja de como la he trazado; esta omisión está justificada por el hecho de que existe un consenso general sobre la existencia de normas implícitas, esto es, de normas sin disposición.

${ }^{61}$ Debe recordarse la redefinición del concepto de validez realizada por R. Guastini (1997a), p. 421-422, que, a mi entender, puede ser adaptada a mi distinción de objetos: «mi opinión es que "validez" designa [...] una relación entre una norma y otra norma: validez es conformidad de una norma a las meta-normas que regulan la producción y a las supra-normas que condicionan el posible contenido». Validez es, por tanto, la pertenencia de una norma a un micro-sistema de normas individualizadas sobre la base de criterios reconstruidos por la ciencia jurídica: así, es necesario decir, por ejemplo: «la norma N pertenece al (es válida) derecho de seguros». Obviamente, una norma no puede pertenecer a un micro-sistema sin pertenecer al ordenamiento en su conjunto.

${ }^{62}$ El problema es particularmente importante en relación con los efectos de una revolución o de un golpe de estado, pacífico o no, sobre la continuidad del ordenamiento estatal, pero también conserva su relevancia teórica fuera de los contextos post-revolucionarios. 
luciones de tipo constitucional y, de otro, que la problemática de las teorías más interesantes resulta acrecentada si se postula la aplicación del modelo (el concepto de derecho y de ordenamiento jurídico) a estados de este tipo (sobre todo en el caso de constituciones rígidas, como la italiana). Además, como ha señalado Scarpelli ${ }^{63}$, la obra del más importante teórico positivista ha estado influida, o por lo menos orientada, por el tipo de régimen y de organización estatal «de moda». Hobbes es el teórico del estado centrado en la voluntad del soberano; Kelsen da cuenta de la fragmentación de esta voluntad debida a la distribución piramidal de la competencia; Hart perfecciona el modelo kelseniano abriendo la puerta a la constitución. En efecto, muchos identifican con la constitución a la regla de reconocimiento hartiana (o principio fundamental en sentido scarpelliano) ${ }^{64}$.

Esto debe confrontarse con algunos datos evidentes.

En primer lugar, la referencia natural de las teorías del derecho contemporáneas es el estado constitucional. Si una teoría debe explicar el funcionamiento de algo, ese algo es el ordenamiento jurídico de un estado constitucional. Una teoría que no dé cuenta de la especificidad de la constitución tiene una carencia importante.

En segundo lugar, el problema de la identificación del derecho, de la pertenencia de las normas a un determinado ordenamiento jurídico, no puede ser reducido a una mera cuestión de conformidad con las reglas sobre la producción jurídica. La validez es una categoría conceptual que, si bien puede explicar las posibles relaciones entre las partes de un mismo sistema jurídico, no puede dar cuenta del modo en el que se consideran dos constituciones como pertenecientes al mismo ordenamiento estatal, por no dar más de un ejemplo ${ }^{65}$.

En definitiva, resulta evidente que un teórico positivista no puede eludir la cuestión de los criterios en base a los cuales se establece la continuidad entre dos constituciones sucesivas. Si se responde a esta pregunta, se tocará necesariamente el problema del origen de tales criterios. Algunas constituciones contienen normas sobre su propia revisión; la conformidad con ellas parecería justificar la tesis de la continuidad. Pero, como se ha señala-

${ }^{63}$ Cfr. U. Scarpelli (1989), pp. 461-464.

${ }^{64}$ Cfr. R. Guastini (1997a), pp. 420 y ss.

${ }_{65}$ Tomar en consideración este problema presupone la conciencia de las relaciones complejas que existen entre hecho y teoría, entre hecho y valor, en última instancia, entre ser y deber ser, en el nivel constitucional. De esto es bien consciente L. Ferrajoli (1997), p. 372: «Esta relación circular entre normatividad del derecho y normatividad de la teoría depende del hecho de que el objeto de la teoría, en los sistemas basados en el paradigma constitucional, no es únicamente el derecho, sino también una propuesta de un modelo, o si se quiere un proyecto de derecho -el diseñado por la constitución- y por ello no sólo el ser, sino también el deber ser del derecho mismo». 
do otras veces, el problema se desplazaría a un nivel más alto. ¿Dónde encontramos entonces el famoso criterio último?

El estudio de los criterios, y por tanto también del criterio último, y la aplicación de los mismos, forma parte de la actividad típica del jurista. Los juristas tienen el deber institucional de ocuparse de este cuestión. El juez (dejo de lado aquí, por no ser paradigmática, la figura del juez constitucional), se podría decir, tiene cosas más importantes que hacer: decidir casos concretos; el legislador no tiene ningún motivo para hacerse esta pregunta: si se la planteara, parecería el propietario de un terreno que se pregunta sobre el origen del sol que irradia y hace crecer sus plantaciones.

\section{Conclusión}

Como el título de mi exposición seguramente ha anticipado, mi objetivo es bastante más modesto que el que conduce al descubrimiento o a la creación de los criterios últimos en base a los cuales se asegura la continuidad de un ordenamiento estatal.

Lo que quiero demostrar es que los juristas, si se considera el derecho como lenguaje -bien entendido esto-, tienen un papel fundamental en la determinación de todos los criterios de identificación: desde los criterios de validez y los criterios de legitimidad constitucional hasta los criterios últimos.

Para adelantarme a las eventuales objeciones precisaré que, si bien mi discurso tiene una única razón de ser, mi tesis puede ser descompuesta en dos tesis autónomas, de las cuales una resulta creíble y la otra parece más bien el resultado de un razonamiento por reducción al absurdo.

(1) La primera tesis se refiere a la naturaleza del discurso de los juristas: el discurso de los juristas es siempre, al mismo tiempo, interno y externo.

En efecto, si aceptamos la teoría de los niveles del discurso, o de los niveles del lenguaje, podemos decir que cuando un jurista sube un nivel se sitúa en un punto de vista externo respecto del objeto del discurso expresado en el nivel inferior, pero, sin embargo, se coloca en una perspectiva interna respecto al objeto del discurso que comienza subiendo de nivel; este procedimiento se repite en cada nivel de discurso imaginable pero, en un cierto punto, ha de terminar. Por usar la famosa parábola wittgensteiniana de la escalera, se puede decir que el jurista, en el extremo más alto de la escalera, si sigue subiendo, pierde el contacto con la realidad que quiere describir o, mejor, sobre la cual quiere escribir; y -por seguir jugando con la metáforasi se sitúa al pie de la escalera, se sitúa en el nivel del antropólogo o del sociólogo que describe hechos y regularidades desde el exterior. El nivel más alto de la escalera es donde se encuentran los discursos de los filósofos del derecho, que elaboran las categorías fundamentales del pensamiento jurídi- 
co; su objeto es el pensamiento jurídico. Ellos son externos respecto al derecho, a lo jurídico, que, en cierto sentido, se queda en el nivel de abajo. Si se sostiene que el discurso de estos teóricos es interno, es necesario hacerlo con referencia a un conjunto de reglas distintas de las reglas de conducta y distintas también -si se ocupan bien- de la regla de reconocimiento del sistema. Adoptan -en mi opinión- un punto de vista interno en relación con una determinada tradición de investigación filosófica. Como muchos han sostenido, una tradición, entendida en este sentido, incluye al menos una concepción de la racionalidad y una concepción de la justicia ${ }^{66}$. El significado de la tesis de Scarpelli es, quizá, que el positivismo jurídico constituye una tradición en este sentido. La pregunta que se impone ahora hace referencia a la posibilidad, por parte de la tradición constitucionalista más reciente, de adoptar la tradición positivista ${ }^{67}$.

Dedicaré ahora algunas palabras a explicar por qué, en el título de mi exposición, hablo de rostros de la ciencia jurídica. El jurista, en mi opinión, tiene tres rostros, tres miradas. El primero, dirigido hacia arriba, busca y acepta los instrumentos de trabajo: los códigos anotados, las monografías, las teorías del derecho y cualquier cosa que considere necesaria para el desarrollo de su trabajo. El segundo rostro está dirigido hacia la comunidad jurídica a la que el jurista pertenece; es consciente de tener el poder de modificar el contenido de las creencias de los destinatarios de las normas y de los funcionarios, su labor constituirá un paso adelante en la constitución del lenguaje jurídico; este rostro escribe su nombre entre los autores del derecho como lenguaje. Por último, el tercer rostro es el que se quiere percibir desde un punto de vista externo: un rostro ciego que se limita a «reiterar», a repetir, el discurso de otros. Este rostro ciego, recortado entre el rostro curioso que busca y acepta y el rostro orgulloso del que crea, no es más que una ficción, porque no repite nada que no provenga de su sensibilidad jurídica.

Para terminar, trataré de dar sentido al término inscripción utilizado en el título de mi trabajo, también para procurar suscitar un interés suplemen-

${ }^{66}$ Cfr. A. MacIntyre (1988) y (1990) y, para un estudio en italiano, B. Pastore (1990). Por tanto, es la tradición la que proporciona al conocimiento del derecho aquellos vínculos fuertes de los que habla V. Villa (1997), p. 845: «el problema central [...] es el de la determinación de los vínculos fuertes para el conocimiento que, en ausencia de la verdad como correspondencia, ponen un límite a la "libre proliferación de los esquemas" y permiten valoraciones comparativas, en términos de mayor o menor corrección o rightness». Villa, por otra parte, parece conocer bien la utilidad, en relación con este fin, del concepto de tradición (cfr. V. Villa (1993), p. 223), que precisamente ofrece parámetros para valorar la corrección de un razonamiento y la adecuación de sus premisas. Por tanto, no es que V. Villa (1997a), p. 850, nota, explorando las posibles vías que conducen a la solución del problema, haga referencia a las afirmaciones de H.L.A. Hart (1961), cap. IX, sobre el contenido mínimo de derecho natural.

${ }^{67}$ Sobre las difíciles relaciones entre positivismo y constitucionalismo, cfr. L. Prieto Sanchís (1996) y M. Troper (1996). 
tario. La idea que me ha incitado a hablar de inscripción del derecho nace de la consideración acerca de qué eran las inscripciones en piedra u otros materiales de las poblaciones primitivas: ¿qué sentido tienen estas inscripciones? ¿Son descripciones de la vida social o reglas que gobernaban la sociedad? Importa poco. Lo que importa es que aquellos que llevaban a cabo esas inscripciones, poseían un instrumento para traducir en signos lo que para la mayor parte de los miembros de sus comunidad era simplemente vivible y no expresable salvo en el nivel de los sentimientos. Desde siempre ha existido una categoría de sujetos dotados de un cierto saber y de un cierto poder para escribir lo que es y lo que debe ser, sujetos dotados de autoridad. Hoy tales sujetos son los profesores universitarios; y la autoridad reconocida a una cátedra prestigiosa, en cuanto autoridad reconocida espontáneamente -no por temor a sanciones o por motivos en alguna medida prudenciales, como ocurre con la autoridad reconocida a los funcionarios-, no tiene paralelo en el mundo político-institucional ${ }^{68}$.

(2) La segunda tesis, como ya he dicho, sólo tiene sentido si se comparte el punto de vista teórico que considera el derecho como lenguaje.

Desde esta perspectiva, el poder de crear normas, de determinar los criterios para su identificación así como los criterios con los que investigar la unidad del ordenamiento estatal, se desplazan a las manos de los juristas ${ }^{69}$.

El derecho no sería, por tanto, creación del legislador ${ }^{70}$-que adoptaría el papel de medium- ni de los jueces, sino de los juristas académicos, que escriben los libros, que ejercen poder sobre sus jóvenes estudiantes que un día serán jueces o legisladores.

La consecuencia más importante de una propuesta téorica tan contraintuitiva es la resolución del problema de la identificación de la categoría de los jueces y de la identificación de la regla de reconocimiento. Como es sa-

${ }^{68}$ Es en cierto sentido significativo que la portada de un reciente volumen sobre derecho y lenguaje, U. Scarpelli - P. Di Lucia (1994), muestra una representación del Código de Hamurabi, una inscripción.

${ }^{69}$ Esta parece ser, al menos según G. Tarello (1980), p. 57-58, nota, una situación auspiciada por la Escuela Histórica: «también la doctrina de la interpretación de la Escuela histórica tiende a producir, mediante el uso de la culturización ideológica (sea con la propaganda en los libros de derecho, sea con la instrucción de futuros operadores en las facultades jurídicas), una subordinación de la magistratura a decisiones políticas pertenecientes a otro lugar: en particular, a las decisiones políticas (no de otros órganos de algún Estado, sino) de la clase o rango de los juristas [...] La escuela histórica tratando de limitar la interpretación jurídica y, en general, la individualización del derecho objetivo al ámbito (bien definido socialmente) de los juristas (académicos), se propone, entre otros, sustraer el juicio de la dependencia que la magistratura, en cuanto cuerpo de funcionarios estatales, tenía frente a la organización estatal [...]».

${ }^{70}$ Sobre la no primacía del legislador en los estados con una constitución rígida, cfr. R. Guastini (1997a), p. 415. 
bido, en esta empresa, el riesgo de círculo vicioso o de ruptura con los dominios del positivismo era difícil de evitar.

Dada la prioridad lógica e histórica del jurista respecto del juez y del ordenamiento jurídico en sentido moderno, el problema es, al menos, desplazado. En efecto, donde el jurista vive una existencia separada e independiente de las instituciones jurídicas, sólo permanece el problema del control de su actividad. El jurista no forma parte de la organización estatal; queda, constantemente, fuera y no puede por ello valorar la fecha de nacimiento y de muerte de la misma. Confiándole el deber de establecer quiénes son los jueces no se cae en ningún círculo vicioso, sencillamente porque el jurista ocupa una posición de prioridad respecto de cualquier ordenamiento estatal y por ello respecto de cualquier institución jurídica.

Por lo se refiere al control al que someter esta actividad creativa, basta recordar que el jurista no es libre, está anclado a una tradición jurídica de la que forma parte y que le proporciona, al menos en parte, los materiales para construir un ordenamiento jurídico.

Esta tradición lo limita, porque le suministra modelos de razonamiento y una idea de justicia. Se puede simplificar la estructura piramidal del pensamiento jurídico diciendo que la tradición provee concepciones acerca de la justicia y la racionalidad que, adaptadas a los fines jurídicos por los filósofos del derecho, sirven de instrumentos a los teóricos del derecho para elaborar conceptos de derecho que los teóricos generales del derecho utilizan para establecer los criterios de individualización de las reglas de reconocimiento que serán usadas en distintos niveles por la ciencia jurídica, la dogmática jurídica y la doctrina para determinar las instituciones y el contenido particular de un ordenamiento jurídico. Pero lo que no debe olvidarse es que, al prescindir de la actividad desarrollada, los juristas en su conjunto pertenecen a, y aceptan las reglas de, una tradición filosófico-jurídica, y se colocan, respecto de ella, en un punto de vista interno.

Por lo tanto, las dos tesis están ligadas entre sí y ambas constituyen, en mi opinión, un desarrollo, quizá catastrófico, pero legítimo, de una teoría del derecho felizmente casada con la filosofía del lenguaje, la hermenéutica jurídica y el constitucionalismo.

La posición sostenida por mí, en la medida en que atribuye a los juristas un rango preexistente al derecho positivo, poder creativo, podría ser acusada de iusnaturalismo. Esta acusación sugiere la necesidad de revisar, tras las teorías positivistas que han mejorado la de Hart, cuántas no merecen esta acusación.

Como he adelantado al principio de esta exposición, mi intento no es normativo y queda absolutamente intacta la posibilidad de escoger otros caminos, de adoptar otras premisas filosóficas, y de llegar a otras teorías jurí- 
dicas, pero sin olvidar que probablemente todos los caminos conduzcan inevitablemente a formas de iusnaturalismo o de realismo jurídico.

\section{Bibliografía}

AARNIO, AULIS (1987), The Rational as Reasonable. A Treatise on Legal Justification, Dordrecht, D. Reidel Publishing Co.

ALCHOURRÓN, CARLOS E. - BULYGIN, EUGENIO (1971), Normative Systems, Wien, Springler Verlag.

ALCHOURRÓN, CARLOS E. - BULYGIN, EUGENIO (1981), «The Expressive Conception of Norms», trad. castellana ahora en C. E. Alchourrón - E. Bulygin (1991), pp. 121-154.

ALCHOURRÓN, CARLOS E. - BULYGIN, EUGENIO (1982), «Definiciones y normas», ahora en C. E. Alchourrón - E. Bulygin (1991), pp. 439-464.

ALCHOURRÓN, CARLOS E. - BULYGIN, EUGENIO (1991), Análisis lógico y derecho, Madrid, Centro de Estudios Constitucionales.

ATIENZA, MANUEL - RUIZ MANERO, JUAN (1996), Las piezas del derecho. Teoría de los enunciados jurídicos, Barcelona, Ariel.

BARBERIS, MAURO (1990a), Il diritto come discorso e come comportamento, Torino, Giappichelli.

BARBERIS, MAURO (1990b), «Regole e linguaggio: primi elementi per la critica del prescrittivismo», en Analisi e diritto 1990. Ricerche di giurisprudenza analitica, Torino, Giappichelli.

BAYÓN MOHÍNO, JUAN CARLOS (1991a), La Normatividad del Derecho. Deber Jurídico y Razones para la Acción, Madrid, Centro de Estudios Constitucionales.

BAYÓN MOHÍNO, JUAN CARLOS (1991b), «Razones y reglas: sobre el concepto de "razón excluyente" de Joseph Raz», Doxa, 10.

BAYÓN MOHÍNO, JUAN CARLOS (1991c), «Proposiciones normativas e indeterminación del derecho», ponencia presentada en el Congreso de Vaquerías Córdoba, inédito.

BAYÓN MOHÍNO, JUAN CARLOS (1996), «Partecipanti, osservatori, e identificazione del diritto», en Analisi e diritto 1996. Ricerche di giurisprudenza analitica, Torino, Giappichelli.

BOBBIO, NORBERTO (1966), «Considerazioni in margine», Rivista di Filosofia, 2.

BULYGIN, EUGENIO (1976), «Sobre la regla de reconocimiento», ahora en C. E. Alchourrón - E. Bulygin (1991), pp. 383-392 [trad. italiana en E. Bulygin (1995)].

BULYGIN, EUGENIO (1991a), «Algunas consideraciones sobre los sistemas jurídicos», Doxa, 9 [trad. italiana en E. Bulygin (1995c)].

BULYGIN, EUGENIO (1991b), «Regla de reconocimiento: ¿Norma de obligación o criterio conceptual? Réplica a Juan Ruiz Manero», Doxa, 9.

BULYGIN, EUGENIO (1995), Norma, validità, sistemi normativi, Torino, Giappichelli. 
CALSAMIGLIA, ALBERT (1996), «Una visione del diritto dal punto di vista del partecipante», en Analisi e diritto 1996. Ricerche di giurisprudenza analitica, Torino, Giappichelli.

CARACCIOLO, RICARDO (1988), El sistema jurídico. Problemas actuales, Madrid, Centro de Estudios Constitucionales.

CARACCIOLO, RICARDO (1991), «Sistema jurídico y regla de reconocimiento», Doxa, 9.

CATANIA, ALFONSO (1987), Il diritto tra forza e consenso, Napoli, Ed. scientifiche italiane.

CHIASSONI, PIERLUIGI (1996), «Osservatori positivistici e quinte colonne», en Analisi e diritto 1996. Ricerche di giurisprudenza analitica, Torino, Giappichelli.

COHEN, JONATHAN (1992), An Essay on Belief and Acceptance, Oxford, Clarendon Press.

COMANDUCCI, PAOLO (1994), «Aarnio ed il problema della certezza del diritto», en Analisi e diritto 1994. Ricerche di giurisprudenza analitica, Torino, Giappichelli.

CONTE, AMEDEO G. (1985a), «Materiali per una tipologia delle regole», Materiali per una storia della cultura giuridica, 2, pp. 345-368.

CONTE, AMEDEO G. (1985b), Nove studi sul linguaggio normativo, Torino, Giappichelli.

FERRAJOLI, LUIGI (1997), «Filosofia analitica del diritto e dimensione pragmatica della scienza giuridica», en L. Gianformaggio - M. Jori (1997).

GIANFORMAGGIO, LETIZIA - JORI, MARIO (a cura di) (1997), Scritti per Uberto Scarpelli, Milano, Giuffré.

GUASTINI, RICCARDO (1997a), «Conoscenza senza accettazione», en L. Gianformaggio - M. Jori (1997).

GUASTINI, RICCARDO (1997b), «Aspetti notevoli di Normative Systems», en Analisi e diritto 1997. Ricerche di giurisprudenza analitica, Torino, Giappiche1 li.

HACKER, PETER MICHAEL STEPHAN (1966), «Sull'uso di “dovere”», Rivista di filosofia, 2.

HART, HERBERT LIONEL ADOLPHUS (1961), The Concept of Law, London, Oxford University Press.

HART, HERBERT LIONEL ADOLPHUS (1982), Essays on Bentham. Studies in Jurisprudence and Political Theory, Oxford, Clarendon Press.

HART, HERBERT LIONEL ADOLPHUS (1983), Essays in Jurisprudence and Philosophy, Oxford, Clarendon Press.

JORI, MARIO (1985a), «Scienza giuridica e scienze naturali», Materiali per una storia della cultura giuridica, 2, pp. 423-439.

JORI, MARIO (1985b), Saggi di metagiurisprudenza, Milano, Giuffré.

MACCORMICK, NEIL (1978), Legal Reasoning and Legal Theory, Oxford, Clarendon Press.

MACCORMICK, NEIL (1981), H. L. A. Hart, Stanford, Stanford University Press.

MACCORMICK, NEIL (1982), «Law, Morality and Positivism», ahora en N. MacCormick - O. Weinberger (1986). 
MACCORMICK, NEIL - WEINBERGER, OTA (1986), An Institutional Theory of Law. New Approaches to Legal Positivism, Dordrecht, Reidel.

MACINTYRE, ALASDAIR (1988), Whose Justice? Which Rationality?, London, Duckworth.

MACINTYRE, ALASDAIR (1990), Three Rival Versions of Moral Enquiry. Encyclopaedia, Genealogy and Tradition, London, Duckworth.

MARTIN, MICHAEL (1987), The Legal Philosophy of H. L. A. Hart. A Critical Appraisal, Philadelphia, Temple University Press.

MOLES, ROBERT N. (1987), Definition and Rules in Legal Theory. A Reassessment of H.L.A. Hart and the Positivist Tradition, London, Blackwell.

NAVARRO, PABLO E. - REDONDO, MARÍA CRISTINA (1991), «Aceptación y funcionamento del derecho», Doxa, 9 .

NINO, CARLOS SANTIAGO (1985), La validez del derecho, Buenos Aires, Astrea.

OST, FRANÇOIS - VAN DE KERCHOVE, MICHEL (1987), Jalons pour une théorie critique du droit, Bruxelles, Facultés Universitaires Saint-Louis.

OST, FRANÇOIS - VAN DE KERCHOVE, MICHEL (1993), «L'idée de jeu peutelle pretendre au titre de paradigme de la science du droit?», Revue interdisciplinaire d'études juridiques, 30.

PÁRAMO ARGÜELLES, JUAN RAMÓN DE (1984), H. L. A. Hart y la teoría analítica del derecho, Madrid, Centro de Estudios Constitucionales.

PASTORE, BALDASSARRE (1985), «Comandi, diritti, e utilitarismo», Materiali per una storia della cultura giuridica, 2, pp. 535-541.

PRIETO SANCHIS, LUIS (1996), «Costituzionalismo e positivismo», en Analisi e diritto 1996. Ricerche di giurisprudenza analitica, Torino, Giappichelli.

RAMOS PASCUA, JOSÉ ANTONIO (1989), La regla de reconocimiento en la teoria jurídica de H. L. A. Hart, Madrid, Tecnos.

RAZ, JOSEPH (1980), The Concept of Legal System, Oxford, Clarendon Press (1 ${ }^{\mathrm{a}}$ ed.: 1970; trad. italiana de Paolo Comanducci, Il concetto di sistema giuridico, Bologna, Il Mulino, 1977).

RAZ, JOSEPH (1981), «The Purity of the Pure Theory», Revue internationale de philosophie, 35, pp. 441-459.

REDONDO, MARÍA CRISTINA (1996), La noción de razon para la acción en el análisis jurídico, Madrid, Centro de Estudios Constitucionales.

RUIZ MANERO, JUAN (1990), Jurisdicción y normas. Dos estudios sobre función jurisdiccional y teoría del derecho, Madrid, Centro de Estudios Constitucionales.

RUIZ MANERO, JUAN (1991), «Normas independientes, criterios conceptuales, y trucos verbales. Respuesta a Eugenio Bulygin», Doxa, 9 .

SARTORIUS, ROLF (1987), «Positivism and the Foundation of Legal Authority», en R. Gavison (1987).

SCARPELLI, UBERTO (1959), Contributo alla semantica del linguaggio normativo, reimpresión, 1985, Milano, Giuffré.

SCARPELLI, UBERTO (1965), Che cos'è il positivismo giuridico, Milano, Comunità.

SCARPELLI, UBERTO (1982), L'etica senza verità, Bologna, Il Mulino. 
SCARPELLI, UBERTO (1989), «Il positivismo giuridico rivisitato», Rivista di filosofia, $80,3$.

SCARPELLI, UBERTO - DI LUCIA, PAOLO (a cura di) (1994), Il linguaggio del diritto, Milano, Casa editrice ambrosiana.

SHINER, ROGER A. (1992), Norm and Nature. The Movements of Legal Thought, Oxford, Clarendon Press.

TARELlO, GIOVANNI (1974a), Diritto, enunciati, usi. Studi di teoria e metateoria del diritto, Bologna, Il Mulino.

TARELLO, GIOVANNI (1974b), «Linguaggio descrittivo e linguaggio precettivo nei discorsi dei giuristi», ahora en U. Scarpelli, P. Di Lucia (1994).

TARELLO, GIOVANNI (1980), L'interpretazione della legge, Milano, Giuffré.

TROPER, MICHEL (1996), «La nozione di principio sovracostituzionale», en Analisi e diritto 1996. Ricerche di giurisprudenza analitica, Torino, Giappichelli.

VILAJOSANA, JOSEP M. (1997), «Alcuni problemi di dinamica giuridica», en Analisi e diritto 1997. Ricerche di giurisprudenza analitica, Torino, Giappichelli.

VILLA, VITTORIO (1993), Conoscenza giuridica e diritto positivo. Lezioni di filosofia del diritto, Torino, Giappichelli.

VILLA, VITTORIO (1997a), «Interpretazione giuridica e teorie del significato», en L. Gianformaggio - M. Jori (1997).

VILLA, VITTORIO (1997b), «Teorie giuridiche e giudizi di valore», en Analisi e diritto 1997. Ricerche di giurisprudenza analitica, Torino, Giappichelli.

(Trad. de Daniel González Lagier) 
$\triangle \quad$ DOXA 22 (1999) 